\title{
Comprehensive Reanalysis of Some Data in the Reports Relate to the TCR V $\beta$ Repertoire of Peripheral Blood in the Patients with Different Diseases
}

\author{
Jianwei Zhou* \\ Clinical Laboratory, Affiliated Hospital of Jining Medical College, Jining 272029, PR, China
}

Received: April 19, 2015; Accepted: April 24, 2015; Published: April 28, 2015

*Corresponding author: Jianwei Zhou, Clinical Laboratory, Affiliated Hospital of Jining Medical College, Jining 272029, PR, China, Tel: +86-5372903223; E-mail: immunolife@126.com

\begin{abstract}
Eighteen reports related to Variable region of Beta Chain (V $\beta$ ) of T cell Receptors (TCR) of the patients with leukemia were reanalyzed. In the results, $V \beta 3$ and $V \beta 9$ were the usually predominantly used genes in all the diseases, which including infectious disease, cancers and leukemia. There were common characteristic of TCR V $\beta$ usage in the same kind of disease; while there were specific characters in the different individuals with the same disease. This finding indicated that it may be helpful for the mechanism study or diagnosis of the diseases according to the specific or common features of TCR V $\beta$ usage.
\end{abstract}

Keywords: T cell receptor; Beta chain; Peripheral blood; Leukemia; Cancer; Infectious diseases

\section{Introduction}

In the past fifteen years, there were some studies related to the clonalities of TCR $\alpha$ and $\beta$ heterodimer, especially the clonal expression of $\mathrm{V} \beta$ genes. In these reports, the predominant usage TCR V $\beta$ gene families usually were shown, and these genes were considered as the factors associated with the corresponding diseases by the authors. However, there was no report about an overview aiming at these reports till now. This paper just focused on the reanalysis of the data in the reports. Through this comprehensive analysis, we attempt to find some new ideas which were different from the original authors, and exhibited some novel indications for the researchers of this filed.

\section{Literature Review}

Eighteen reports (1-18) were selected as references to reanalyze, and the inclusion criteria was that the specific predominant usage TCR V $\beta$ genes were clearly listed; if not, it would be excluded. The relative diseases involved Hepatitis Virus B (HBV) infection, Human Immunodeficiency Virus (HIV) infection, Pemphigus vulgaris (PV), Colorectal Cancer (CC), Lung Cancer (LC) and leukemia. Leukemia mainly included Acute Promyelocytic Leukemia (APL), T cell-Acute Lymphoblastic Leukemia (T-ALL), B cell-Acute Lymphoblastic Leukemia (B-ALL), Acute Monoblastic Leukemia (AMoL), Acute Myelogenous Leukemia (AML) and
Chronic Myeloid Leukemia (CML). The details of the useful information extracted from the reports were listed in Table 1.

Generally, there were two V $\beta$ genes which further divided into two subfamilies in the family of 24 TCR V $\beta$ genes: V $\beta 5$ and $V \beta 13$. The former contained V $\beta 5.1$ and $V \beta 5.2$; the later had $V \beta 13.1$ and $V \beta 13.2$. In some references of this study, there were some $V \beta$ genes else which held subfamilies, for example, $V \beta 7$ contained V $\beta 7.1, V \beta 7.2$ and V $\beta 7.3$. These differences probably lied on the different classification standards for the subfamilies. However, the main $V \beta$ gene families' classification was consistent with each other. In order to unify the classification standard and make the data convenient for counting the predominant usage, the numbers of $V \beta$ subfamilies were counted as the total of the corresponding main $\mathrm{V} \beta$ gene family. Besides, a concept of Predominant Usage Frequency (Frequencies) (PUF or PUFs) was applied, and its calculation formula was as following:

$$
\operatorname{PUF}(\%)=\Sigma \mathrm{n} / \Sigma \mathrm{p} \times 100
$$

$\Sigma \mathrm{n}$ : the summary of the times for certain a $\mathrm{V} \beta$ gene which was predominantly used; $\Sigma$ p: the summary of the patients with certain disease or all the patients in the study.

\section{Comprehensive Reanalysis}

In the predominant usage $\mathrm{V} \beta$ genes of all the patients, $\mathrm{V} \beta 3$ were the highest usage genes, the PUF was $18 \%(36 / 200)$; V $\beta 9$ was next to it with the PUF of $17 \%(34 / 200)$, which was followed by V $\beta 5$ with the PUF of $13 \%(26 / 200)$. Both PUFs of V $\beta 13$ and $\mathrm{V} \beta 21$ were $11.5 \%(23 / 200)$. In all of the $24 \mathrm{~V} \beta$ genes, the lowest usage gene was V $\beta 4$ with PUF of $1.5 \%(3 / 200)$; V $\beta 16$ and V $\beta 24$ were second to it and which PUFs were all 2.5\% (5/200) (Figure 1).

As shown in Figure 2, in HBV infection, the gene with highest PUF was V $\beta 11$ (28\%), V $\beta 12$ was next to it with PUF of $22 \%$. The PUFs of $\mathrm{V} \beta 8, \mathrm{~V} \beta 9$ and $\mathrm{V} \beta 10$ were all $16 \%$; in HIV infection, the gene with highest PUF was V $\beta 5$ (37\%), V $\beta 7$ was next to it in which PUF was $32 \%$. The PUFs of V $\beta 9$ and V $\beta 20$ were both $26 \%$. According to the predominant usage frequencies of TCR V $\beta$ specific to different diseases, the features of Complementarity 
Determining Region 3 (CDR3) of TCR V $\beta$ were reanalyzed with histograms.

\section{Discussion}

As the authors shown, there were different predominant usage gene families in different diseases. For example, $V \beta 11$ and $V \beta 12$ expressed in HBV infection; V 33 and V $\beta 13$ in CC; V $\beta 12, V \beta 21$ and V $\beta 23$ in APL; and so on. In most viewpoints of the researchers, these different predominant usage genes were just specific to the different diseases and probably represent the different features of the corresponding diseases. However, in our opinion, there were some insufficiencies in the perfect analysis for every report, and there would be more meaning to comprehensively analyze these research results.

In $24 \mathrm{~V} \beta$ gene families of all the cases, TCR V $\beta 3$ was the most advantageous usage gene in the diseases except HBV and HIV infections. This probably indicated that V $\beta 3$ always was the predominantly used in most of diseases beside virus infections. $V \beta 9$ and V $\beta 13$ even existed in all the diseases which except for APL and AML, respectively. This result showed that there were no specificities for their expression to the diseases; but if the expression absence of the two genes could indicate the occurrence of APL or AML needed for further study. As the gene families of low PUFs, V $\beta 4$ was predominantly used in HBV infection, CC and APL; while V $\beta 16$ was the advantageous expression gene for HBV infection, AML and CML. These results showed that V $\beta 4$ and V $\beta 16$ probably were the diagnosis indices for HBV, CC, APL, AML and CML; especially, $\mathrm{V} \beta 4$ plus $\mathrm{V} \beta 16$ may be more helpful for the diagnosis of HBV infection because both had relative high PUFs in this disease.

According to different PUFs of TCR V $\beta$ in different diseases, the histograms were designed. As Figure 2 shown, the columns of different heights in the histogram represented the predominant usage frequencies of $V \beta$ subfamilies. Obviously, the panorama of each histogram looked like a key, and the prominent columns were as same as the kits of the key. There were different kits in different diseases, for example, the components of the kits for HBV infection were V $\beta 2-\mathrm{V} \beta 4-\mathrm{V} \beta 5$-V $\beta 8-\mathrm{V} \beta 9-\mathrm{V} \beta 10-\mathrm{V} \beta 11-\mathrm{V} \beta 12$ $\mathrm{V} \beta 13-\mathrm{V} \beta 15-\mathrm{V} \beta 16-\mathrm{V} \beta 17-\mathrm{V} \beta 18-\mathrm{V} \beta 21-\mathrm{V} \beta 22-\mathrm{V} \beta 23-\mathrm{V} \beta 24$; those were $\mathrm{V} \beta 5-\mathrm{V} \beta 7-\mathrm{V} \beta 9-\mathrm{V} \beta 13-\mathrm{V} \beta 20$ in HIV infection; while those were $V \beta 2-V \beta 7-V \beta 9-V \beta 21$ in AMOL. Except for the components, and the height of the column determined by PUF was also the factor which determined the key's feature. The higher the frequency of the TCR V $\beta$ gene family was, the higher the kit of the key would be. Therefore, to some extent, the key presented the total characterization of TCR V $\beta$ skewness of the patients with certain a disease. As we known, the skewness of TCR V $\beta$ specific to the associated antigen of the corresponding disease, so the key formed with the predominant usage genes could be taken as the whole skewness of TCR V $\beta$; in another words, it was a specific key to the certain a disease. There is a proverb in China which says that 'Open different locks with different keys'. Accordingly, there should be a key specific to every disease, such as various pathogen infections, colorectal cancer, leukemia, and so on.

\section{Conclusion}

Through the reanalysis of the data in the articles related to TCR V $\beta$ predominant usage, we found the total usage characteristics of $24 \mathrm{~V} \beta$ gene families in the different diseases, and the individual features of the gene usage in each of the disease. To our understanding, these results probably pose a new idea or a novel viewpoint for analyzing and using the skewness of TCR for the researchers. For example, if the histogram of TCR

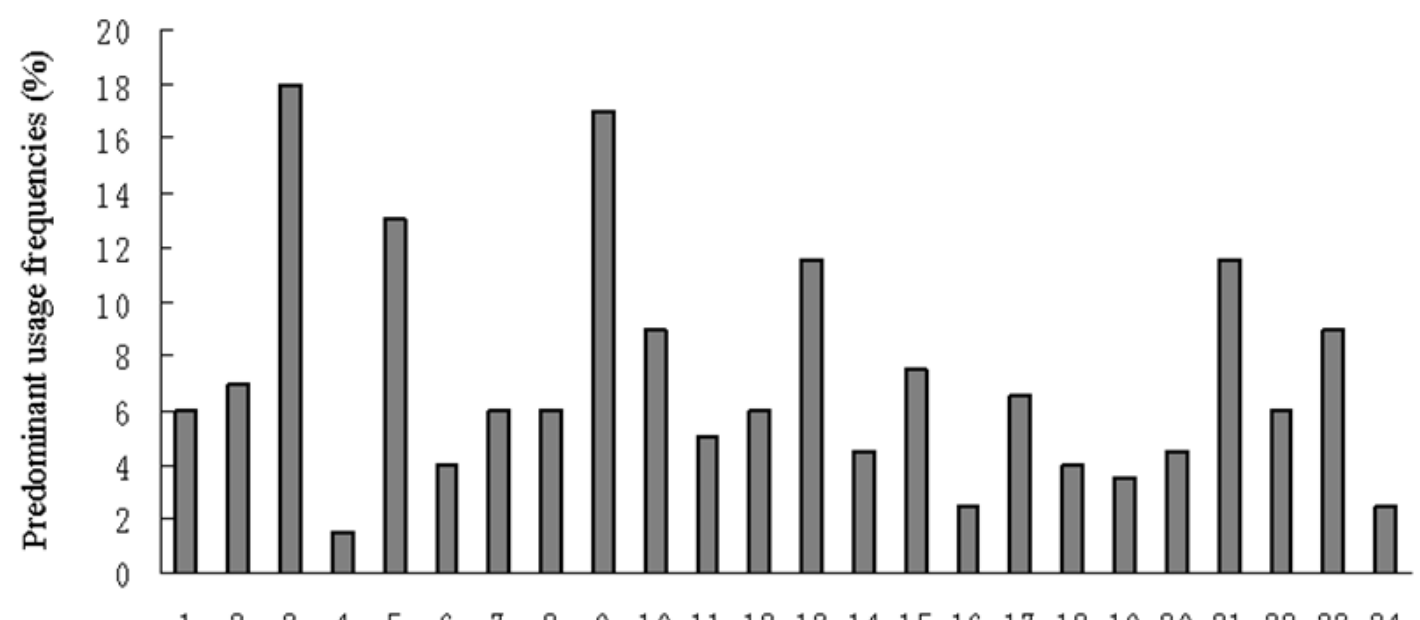

Different $V B$ genes of $T$ cell receptor

In all the patients, V 33 were the highest usage genes, the PUF was 18\% (36/200); V $\beta 9$ was next to it with the PUF of $17 \%$ (34/200), which was followed by V $\beta 5$ with the PUF of $13 \%$ (26/200). Both PUFs of V $\beta 13$ and V $\beta 21$ were $11.5 \%(23 / 200)$. In all of the $24 \mathrm{~V} \beta$ genes, the lowest usage gene was V $\beta 4$ with PUF of 1.5\% (3/200); V $\beta 16$ and V $\beta 24$ were second to it and which PUFs were both 2.5\% (5/200).

Figure 1: The total predominant usage frequencies of TCR V $\beta$ genes summed from the patients with different diseases. 

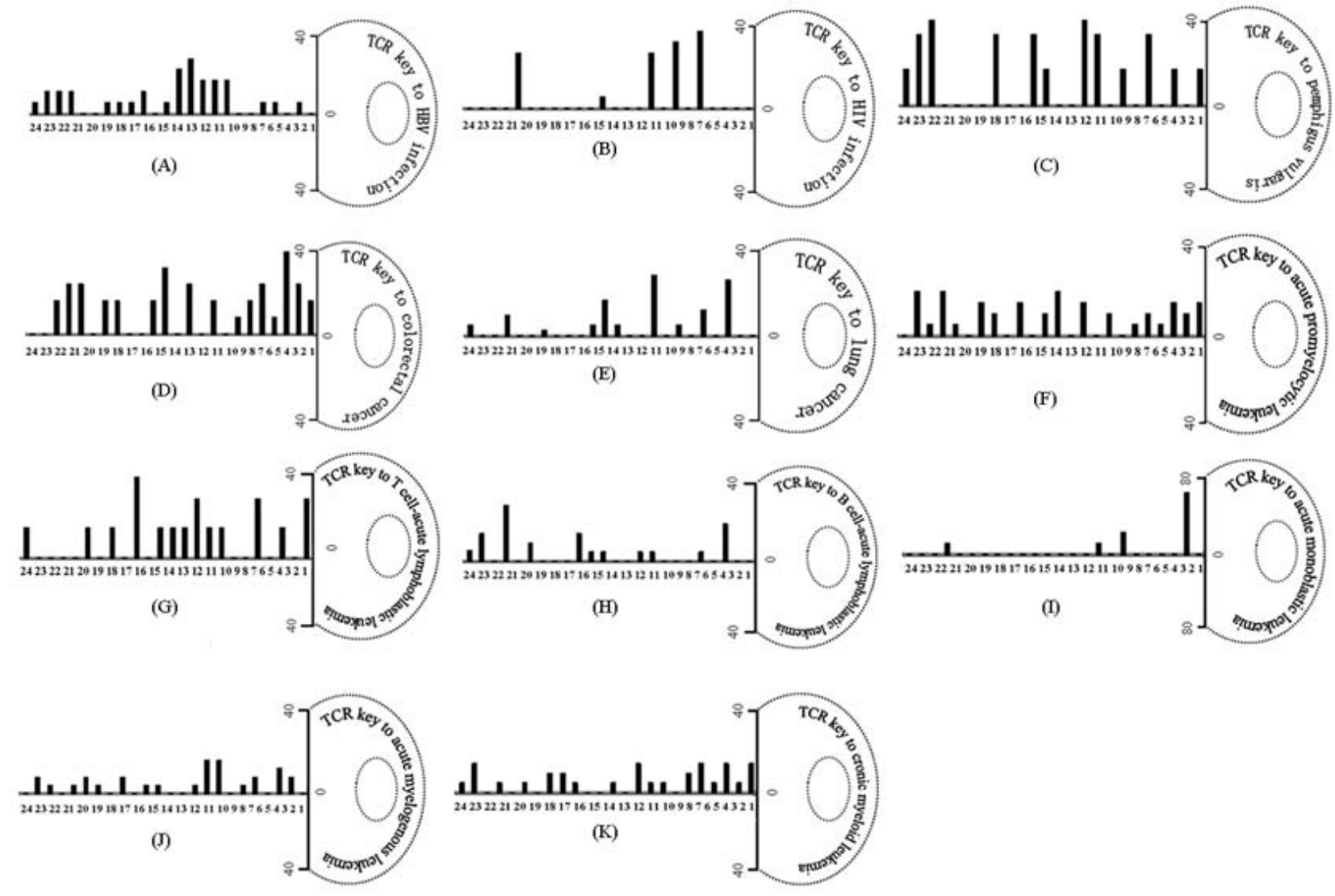

According to the reports relates to the predominant usage frequencies of TCR V $\beta$ specific to different diseases, the features of Complementarity Determining Region 3 (CDR3) of TCR V $\beta$ were reanalyzed with histograms respectively. The columns with different heights represent different predominant usage frequencies of $\mathrm{V} \beta$ subfamilies (including the monoclonal, biclonal and oligoclonal gene families), and the polyclonal and low-expression genes are ignored in this analysis. It is easy to see that each merged gram likes a big key, which probably reflects the characteristics of the skewness of T Cell Receptor (TCR) specific to the corresponding disease. (A) The TCR key to Hepatitis Virus B (HBV) infection; (B) The TCR key to Human Immunodeficiency Virus (HIV) infection; (C) The TCR key to Pemphigus vulgaris; (D) The TCR key to colorectal cancer; (E) The TCR key to lung cancer; (F) The TCR key to acute promyelocytic leukemia; (G) The TCR key to T cell-acute lymphoblastic leukemia; (H) The TCR key to B cell-acute lymphoblastic leukemia ; (I) The TCR key to acute monoblastic leukemia; (J) The TCR key to acute myelogenous leukemia; (K) The TCR key to chronic myeloid leukemia.

Figure 2: The different "keys" specific to different disease formed with the predominant usage frequencies of TCR V $\beta$ genes in PBMC of the corresponding patients.

Table 1: The summary of the predominant usage TCR V $\beta$ genes in PBMC of all the patients with different diseases extracted from the references.

\begin{tabular}{|c|c|c|c|}
\hline Diseases & $\begin{array}{l}\text { Reference } \\
\text { Number }\end{array}$ & Predominant usage V $\beta$ genes from the corresponding reference & Total of cases \\
\hline \multirow{3}{*}{$\begin{array}{l}\text { HBV } \\
\text { infection }\end{array}$} & [1] & P1: V $\beta 8, V \beta 24, V \beta 10 ; \mathbf{P 2 :} V \beta 12, V \beta 11, V \beta 15, V \beta 22, V \beta 23$ & \multirow{3}{*}{18} \\
\hline & [2] & 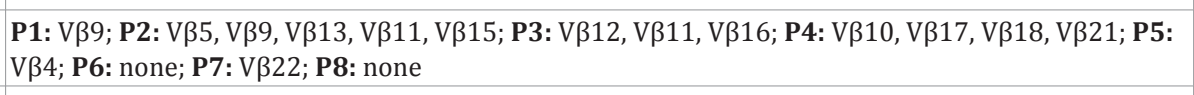 & \\
\hline & [3] & 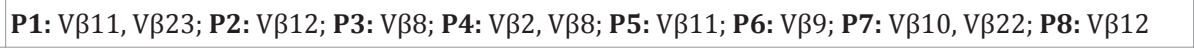 & \\
\hline HIV Infection & {$[4]$} & 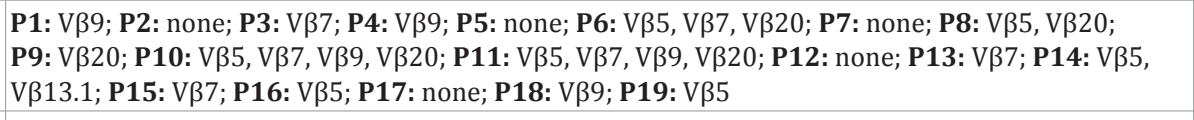 & 19 \\
\hline PV & [5] & $\begin{array}{l}\text { P1: V } \beta 1, V \beta 3, V \beta 7, V \beta 17 ; \mathbf{P 2}: V \beta 10, V \beta 13, V \beta 14 ; \mathbf{P 3}: V \beta 10, V \beta 14, V \beta 22, V \beta 23 ; \mathbf{P 4}: V \beta 5, V \beta 9, V \beta 22, \\
V \beta 23 ; \mathbf{P 5}: V \beta 9, V \beta 10, V \beta 22, V \beta 24 ; \mathbf{P 6}: V \beta 5, V \beta 17\end{array}$ & 6 \\
\hline \multirow[b]{2}{*}{$\mathrm{CC}$} & [6] & P1: V $\beta 5$; P2: none; P3: V $\beta 2, V \beta 3 ; \mathbf{P 4 : ~ V \beta 3 ; ~ P 5 : ~ n o n e ; ~ P 6 : ~ V ~} \beta 2, V \beta 3$ & \multirow[b]{2}{*}{13} \\
\hline & [7] & $\begin{array}{l}\text { P1: V } \beta 1, V \beta 7, V \beta 9, V \beta 11, V \beta 22 ; \mathbf{P} 2: V \beta 2, V \beta 3, V \beta 4, V \beta 5.2, V \beta 13.1, V \beta 13.2, V \beta 17, V \beta 18, V \beta 20, V \beta 21 ; \\
\text { P3: V } \beta 1, V \beta 3, V \beta 5.2, V \beta 6, V \beta 9, V \beta 11 ; \mathbf{P 4}: V \beta 20 ; P 5: V \beta 6, V \beta 14, V \beta 17, V \beta 21 ; \mathbf{P 6}: V \beta 13.1, V \beta 14, \\
V \beta 22 ; \text { P7: V } \beta 11, V \beta 13.2, V \beta 18, V \beta 20, V \beta 21\end{array}$ & \\
\hline
\end{tabular}




\begin{tabular}{|c|c|c|c|}
\hline APL & {$[8,9]$} & 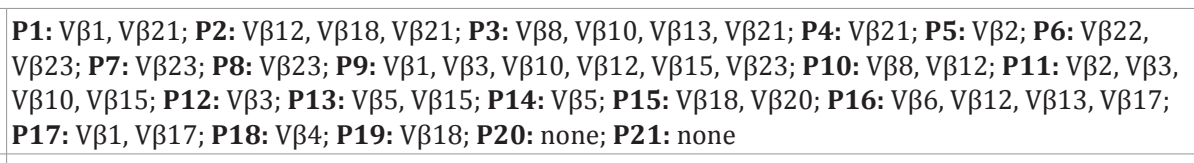 & 21 \\
\hline \multirow{2}{*}{ T-ALL } & [10] & 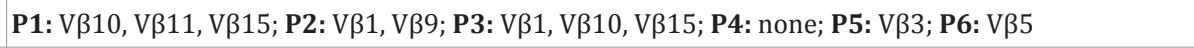 & \multirow[b]{2}{*}{7} \\
\hline & [11] & P1: V $\beta 5.1, V \beta 8, V \beta 12, V \beta 13.1, V \beta 15, V \beta 17, V \beta 19, V \beta 24$ & \\
\hline \multirow{2}{*}{ B-ALL } & [12] & 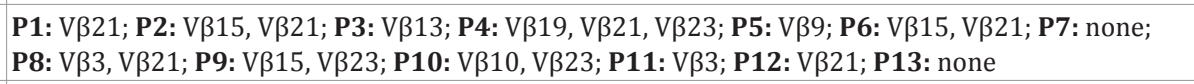 & \multirow{2}{*}{17} \\
\hline & [11] & 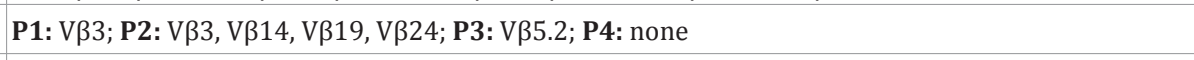 & \\
\hline AML & [13] & 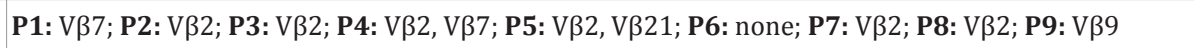 & 9 \\
\hline \multirow{4}{*}{ AMoL } & [14] & 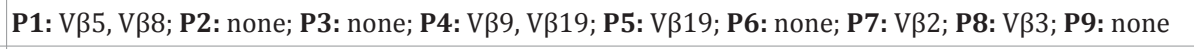 & \multirow[b]{4}{*}{25} \\
\hline & [15] & 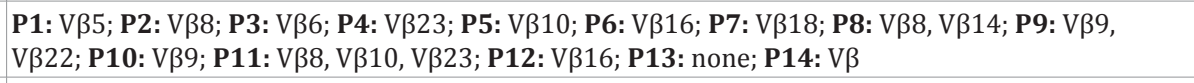 & \\
\hline & [11] & P1: V $\beta 3, V \beta 13.1 ; \mathbf{P 2}: \mathrm{V} \beta 3, \mathrm{~V} \beta 9$ & \\
\hline & [16] & 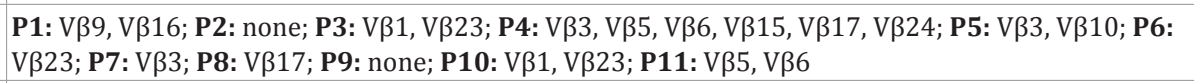 & \\
\hline CML & [17] & 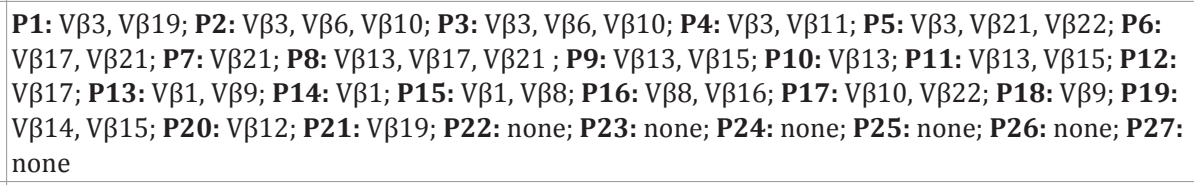 & 22 \\
\hline LC & [18] & $\begin{array}{l}\text { Vß3: 11; V } \beta 5.2: 2 ; \mathbf{V} \beta 5.3: 2 ; \mathbf{V} \beta 7.2: 2 ; \mathbf{V} \beta 9: 12 ; \mathbf{V} \beta 12: 2 ; \mathbf{V} \beta 13.2: 7 ; \mathbf{V} \beta 14: 2 ; \mathbf{V} \beta 18: 1 ; \mathbf{V} \beta 21: 4 ; \\
\mathbf{V} \beta 23: 2\end{array}$ & 43 \\
\hline
\end{tabular}

$\mathrm{V} \beta$ of a patient looks like that of AMoL, this may be helpful for the physician to make a diagnosis; and if the heights of predominant columns decrease, this may, indicate that the treatment is proper for the patient in clinic. Of course, this hypothesis needs lots of studies to prove by the researchers in future.

\section{Acknowledgements}

The work is supported by the Provincial Science and Technology Development Project (No. 2012YD180540), the Provincial Nature Science Foundation (No. ZR2012HL29), the Project of Shandong Province Higher Educational Science and Technology Program (No. J11LF18), the Population and Family Planning Commission (No. (2011)13), and the Development Plan Project of Jining Science and Technology Bureau of Shandong Province (No. (2011) 57, 2014jnjc12 and 2014jnyx14).

\section{References}

1. Yao XS, Diao Y, Sun WB, Luo JM, Qin M, Tang XY, et al. Analysis of the CDR3 length repertoire and the diversity of TCR alpha chain in human peripheral blood T lymphocytes. Cell Mol Immunol. 2007; 4(3): 215220.

2. Zhang GW, Yao XS, Ma SW, Yang CG, Yu YC, Hou JL, et al. Analysis of T cell receptor BV dominant usage and CDR3 sequences during acute exacerbation in patients with chronic hepatitis B. Zhonghua Gan Zang Bing Za Zhi. 2006; 1(1): 23-28.

3. Xiong Y, Song YG, Bi SL, Yan Y. Study of clonality of TCR V $\beta$ gene subfamilies on peripheral blood $\mathrm{CD} 8^{+} \mathrm{T}$ lymphocyte in patients with chronic hepatitis B. Chinese Journal of Immunology. 2011; 27: 751756.

4. Li ZF, Zeng Y, Zhang HJ, Leng WJ, Cheng L, Li Q, et al. Preliminary study on detection of TCR CDR3 spectrum of TCR $\beta$ gene repertoire by using FQ-PCR melting cure in the MSM HIV infected people. Chinese Journal of Health Laboratory Technology. 2014; 24(15): 2138-2140.
5. Wang Q, Zeng K, Zhou Z, Sun LD, Zhou ZG. Spectra typing analysis of complementarity-determining region 3 of T-cell receptor beta chain variable region in peripheral blood mononuclear cells of patients with Pemphigus vulgaris. Academic Journal of Second Military University. 2009; 30(3): 291-294.

6. Li HF, Wan YL, Liu YC, Tang JQ, Wu T, ZHANG Y, et al. The characteristics of TCR repertoire in tumor-infiltrating lymphocytes from rectal cancer. Chinese Journal of Birth Health \& Heredity. 2003; 11(6): 1418.

7. Zhou J, Ma R, Luo R, Sun Y, He X, Sun W, et al. Primary exploration of CDR3 spectratyping and molecular features of TCR $\beta$ chain in the peripheral blood and tissue of patients with colorectal carcinoma. Cancer Epidemiol, 2010; 34(6): 733-740. doi: 10.1016/j. canep.2010.06.010

8. Yang LJ, Li YQ, Chen SH, Zhou YB, Tang J, Wu XL, et al. The feature of clonal expansion of TCR V $\beta$ T cell s from peripheral blood in patients with APL. Journal of Leukemia \& Lymphoma. 2005; 14(4): 205-214.

9. Li Y, Chen S, Yang L, Zhou Y, Wu X, Huang M, et al. Clonal expanded TCR Vbeta T cells in patients with APL. Hematology. 2005; 10(2): 135-139.

10. Huang MJ, Li YQ, Chen SH, Zhou YB, Yang LJ, et al. Clonality and gene repertoire analysis of T-cell receptor $\mathrm{V} \beta$ associated with T-ALL and T cell strains. Immunological Journal. 2004; 20 (6): 439-442.

11. Sun YP, Shi B, Zhu HQ, Tang XY, Ma R, et al. Analysis of TCR CDR3 spectratyping of $\alpha \beta \mathrm{T}$ cells in peripheral blood mononuclear cells with leukemia by using FQ-PCR DNA melting curve technique. Journal of Zunyi Medical University. 2014; 37(1): 39-47.

12. Huang MJ, Li YQ, Chen SH, Yang LJ, Zhou YB, et al. Analysis of T-cell receptor $\mathrm{V} \beta$ gene repertoire and clonality in patients with B-ALL. Cancer research on prevention and treatment. 2004; 31(6): 320-322.

13. Li YQ, Yang LJ, Chen SH, Li RF, Zhang YP, Lu Y, et al. Clonal expansion $\mathrm{T}$ cells identified in acute monoblastic leumia by CDR3 size analysis of TCR V $\beta$ repertoire using RT-PCR and genescan. Chin Med J. 2002; 115(1): 69-71. 
14. Chen SH, Li YQ, Yang LJ, Yu Z, Luo GX. Analysis of clonal expansion of TCR V $\beta$ subfamily T cells associated with AML-M1. Immunological Journal. 2002; 18(5): 353-356.

15. Li FR, Li YQ, Yang LJ, Chen SH, Zhang XL, et al. Analysis of the clonal expansion of TCR V $\beta$ subfamily genes and T cell clonality in AML-M2a using genescan. Journal of modern clinical medical bioengineering. 2001; 7(4): 241-243.

16. Mao P, Luo CR, Zhang YP, Wang CX, Xu YP, Ying Y, et al. Expression and clonal proliferation of TCR V $\beta$ subfamilies of peripheral T-cells in acute myeloid leukemia patients. Journal of Experimental Hematology. 2009; 17(2): 431-436.

17. Li YQ, Yang LJ, Chen SH, Zhang YP, Zhang XL, Luo GX, et al. T cell receptor $\mathrm{V} \beta$ repertoire usage and clonal expansion of $\mathrm{T}$ cells in chronic myelogenous leukemia. Chin Med J. 2004; 117(6): 840-843.

18. Guo NN, Huang SL, Shao HW, Wu FL, Wang H, Wu FL, et al. Study on the expressions of TCR Vbeta subfamily and memory T cells in patients with lung cancer. Journal of Guangdong Pharmaceutical College. 2011; 27(2): 1-5. 